\title{
The effect of moving and static trans-scleral illumination of visual afterimages
}

\author{
ROBERT J. HALL, ${ }^{1}$ HUMAN FACTORS RESEARCH, INC. \\ RICHARD A. MONTY, U.S. ARMY HUMAN ENGINEERING LABORATORIES \\ AND WILLIAM E. WILSONCROFT, SAN FERNANDO VALLEY STATE COLLEGE
}

\begin{abstract}
The inside of the eye was illuminated by shining a small light through the upper eyelid and the sclera. After viewing a bright light flash, Ss closed their eyes and reported the duration of the afterimage under the following conditions: the light on and moving across the $S$ 's eyelid (moving trans-scleral illumination), the light on but stationary (static trans-scleral illumination), and two corresponding control conditions in which the light was turned off (darkness). Results indicate that when the trans-scleral light is moving, afterimages are seen clearly for periods of approximately the same duration as those seen in complete darkness. Howtver, when the trans-scleral illumination is stationary, the duration of the afterimages is significantly reduced. These results are compatible with other afterimage data that suggest that changes within the field after initial stimulation are needed to prolong afterimages.
\end{abstract}

Biochemical bleaching processes are clearly related to the perception of visual afterimages (Brindley, 1959, 1963; Alpern \& Barr, 1961). However, it has long been known that these processes are somewhat flexible because durations of afterimages can be manipulated by events within the visual system following the eliciting stimulation. Helmholtz (1866) cites several studies in which afterimages that have faded in normal ambient light are revived by rapid changes in the illumination level of the viewing field after the eye is stimulated. Evans (1928) reported that slowly flickering lights can prolong afterimages, and Williamson (1945) merely turned the room lights on and off to revive and prolong them. If the stimulated eye is exposed to heterogeneous flickering-light conditions, the afterimages will last longer than if the eye is unstimulated following exposure to the light flash (Hall \& Wilsoncroft, 1964). The perception of such entoptic images as the truly "stabilized" retinal blood vessels is also facilitated by changes within the visual system and inhibited by homogeneous conditions (Hall, 1966). Matteson (1965) has suggested that the adaptation process responsible for the disappearance of both afterimages and stabilized images may be disrupted by changes within the visual field.

The aim of the present study was to determine whether or not the changes produced by a trans-scleral light source would influence the duration of afterimages.

\section{METHOD}

The Ss $(N=12)$ were seated and adjusted to the apparatus, which consisted of a dental "bite-bar" aligned in a scaffolding so that a small lightbulb (G.E. No. 222.25) rested against the S's upper eyelid. A spring-operated motor system moved the bulb between two rails across the $S$ 's eyelid in the two moving conditions.

After Ss adapted to the normal ambient light of the laboratory, they fixated a $5-\mathrm{mm}$ circular aperture in an iris $24 \mathrm{in}$. from one eye; their unstimulated eye was covered with an eyepatch. Afterimages were induced through the aperture by flashing a G.E. Photoflash No. 5 bulb. Immediately following the flash, Ss closed their eyes. Ss were instructed to try to avoid opening the eye, blinking, or making rapid eye movements.

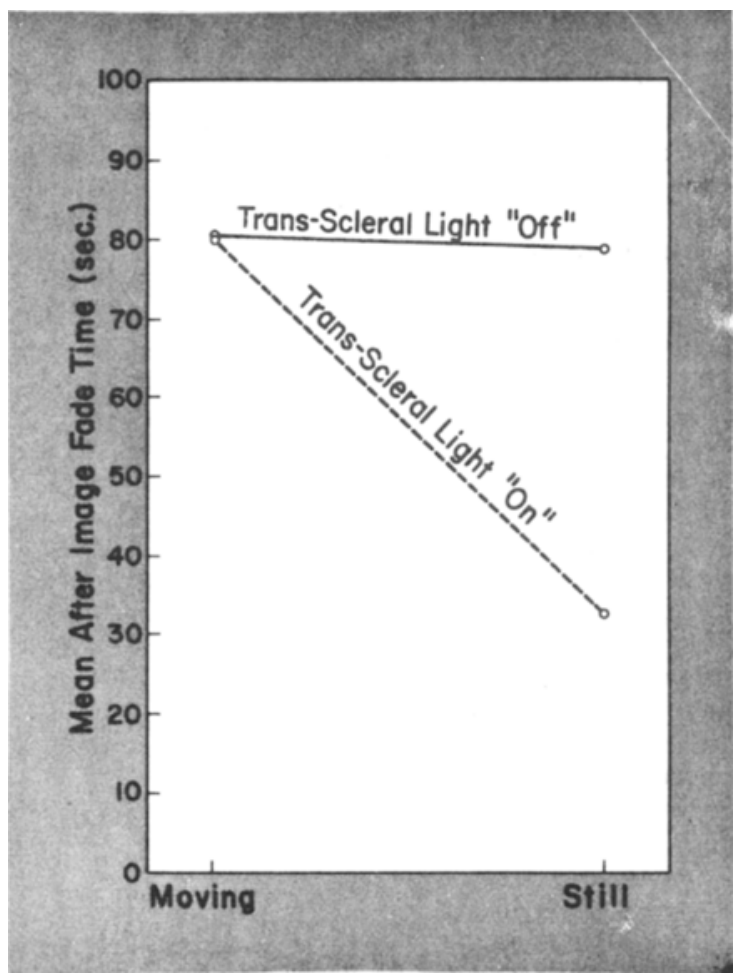

Fig. 1. Effects of trans-scleral illuminant upon the duration of afterimages $(N=12$ Ss with four measures on each $S$ under each condition, total 192).

The Ss reported to $\mathbf{E}$ when the afterimage had completely disappeared, and the elapsed time from the flash until complete fading of the afterimage was recorded.

Trials were alternated between right and left eyes, and a total of 16 responses (two measures for each eye under each of the four conditions) were recorded from each S. A minimum intertrial interval of 3 min was maintained.

The experimental conditions consisted of having the small light source in one of the following modes: turned "on" and moving back and forth across S's eyelid at a rate of 3 cps or turned "on" but remaining stationary. Two light-"off" conditions were included to determine whether or not the movement of the lightbulb against the upper eyelid influenced the duration of the afterimages. These were light turned "off" and moving across S's eyelid and light turned "off" and remaining stationary on S's eyelid.

\section{RESULTS}

The duration scores were subjected to an analysis of variance, where entoptic light (on-off), motion (on-off), and eyes were the main effects. Only the following were significant: trans-scleral light $[F(1,88)=4.96, p<.01]$, motion $[F(1,88)=5.65$, 
$\mathrm{p}<.011$, and the interaction of Scleral Light by Motion $[P(1,88)=4.46, p<.01]$. All other effects failed to reach significance. The results are illustrated in Fig. 1.

Special mention must be made of the light-"on" conditions. Ss reported that when the trans-scleral light was "on" and moving, a flight of colors associated with the afterimage was perceived and was more vivid and distinct than when the light was static. In most instances, the afterimage appeared to pulsate or to shift back and forth between two vivid colors, e.g., yellowish-orange and blue-violet. Ss reported that these changes were correlated with the movement of the trans-scleral source. When the trans-scleral light was static, the duration of the afterimage was significantly reduced (see Fig. 1), and Ss reported less impressive flights of color.

When the interior of the eye was illuminated by a moving trans-scleral light, Ss reported seeing entoptic images of the retinal blood vessels. Entoptic images of the retinal blood vessels have been reported earlier (Hall, 1966), and these entoptic images may have influenced $\mathrm{Ss}$ ' perception of afterimages, although $\mathrm{Ss}$ in the present study were instructed to ignore them and to concentrate on the afterimages.

\section{DISCUSSION}

The major finding of this study was the rapid disappearance of visual afterimages when the interior of the eye was illuminated by a stationary trans-scleral light. This experimental condition is perhaps analogous to that in which Ss, after stimulation, looked at a homogenous bright screen (Hall \& Wilsoncroft, 1964). In both cases, the afterimages disappeared rapidly.

However, movement of the trans-scleral light back and forth across S's eyelid enhanced, or prevented the fading of, afterimages. This may be due, in part, to the directional sensitivity of the retina (Makous, 1968). Reports on the vivid flights of color of the afterimages when using a moving trans-scleral light seem to attest to this directional hypothesis.

The adaptation mechanism responsible for the disappearance of afterimages seems to be enhanced by unchanging illumination after the initial stimulation, whether proximal (within the eye itself by a trans-scleral illumination) or distal (viewing a homogenous field).
In the two control conditions, when the trans-scleral light was turned "off," the data showed a greater variability than with the "on" conditions. The cause of the high variability of the afterimage duration in these "off" conditions, in which the eye remained in darkness, is not clear. Perhaps when the afterimage is followed by darkness, the adaptation level shifts toward scotopic vision, and this shift enhances or maintains the differences between the stimulated and nonstimulated receptors. In any case, it should be noted that, under the conditions used in this study, mechanical displacement or vibration of the eye caused by the movement of the lightbulb across the S's eyelid did not, in itself, affect the duration of the afterimages.

\section{REFERENCES}

ALPERN, M., \& BARR, L. Durations of the after-images of brief light flashes and the theory of the Broca and Sulzer phenomena. Journal of the Optical Society of America, 1961, 52, 219-221.

BRINDLEY, G. S. The discrimination of after-images. Journal of Physiology, 1959, 147, 194-203.

BRINDLEY, G. S. Afterimages. Scientific American, 1963, 209, 84-93.

EVANS, J. N. A clinical method to determine the rate of elimination of after images (eikonoscopy). A merican Journal of Ophthalmology, 1928, $11,194-202$.

HALL, R. J. The effects of moving and stabilized trans-scleral illumination on entoptic images and visual adaptation. Unpublished doctoral dissertation, Claremont Graduate School, 1966.

HALL, R. J., \& WILSONCROFT, W. E. Prolonging visual after images. Psychonomic Science, 1964, 1, 267-268.

HELMHOLTZ, H. L. F. von. Physiological Optics. (1866), Translation: New York: Dover, Vol. II, 1962.

MAKOUS, W. L. A transient Stiles-Crawford effect. Vision Research, 1968, 8, 1271-1284.

MATTESON, H. H. Aftex-images observed with intermittent background illumination. Vision Research, 1965, 5, 123-132.

WILLIAMSON, W. P. After-image perimetry: A rapid method of obtaining visual fields; preliminary report. Archives of Ophthalmology, 1945, 33, 417-422. (Psychological Abstracts, 1945, 19, 127.)

\section{NOTE}

1. Address: Human Factors Research, Inc., Santa Barbara Research Park Goleta, California 93017

(Accepted for publication May 26, 1969.) 